\title{
EVOLUTION OF ENGLISH IN THE INTERNET AGE
}

\author{
Abdu M. Talib Al-Kadi' \\ Rashad Ali Ahmed ${ }^{2}$ \\ ISLT, Carthage University, Tunisia' \\ The University of Memphis, USA ${ }^{2}$ \\ findtalib@gmail.com'; raahmed@memphis.edu²
}

First received: 17 July 2017

Final proof received: 31 January 2018

\begin{abstract}
Although the Internet came into existence in the second half of the twentieth century, its influence on language began to escalate in 1990 onwards. It has drastically changed the way people communicate and use English both in writing and speaking. Consequently, the world has become increasingly interconnected through synchronous and asynchronous communicational scripts, such as SMS, online chat, Yahoo messengers, emails, blogs, and wikis, which have become retrievable as accessible corpora for analysis. These corpora can yield anecdotal evidence of historical language change. The arrival of Web 2.0 tools and applications, such as Facebook, Twitter, Skype, WhatsApp, and Viber, can likewise reveal changes that English has recently undergone. The Internet has given rise to what is arguably a new variety of English that differs from standard varieties. This article provides an account of the development of English from dialects spoken by a small number of people in the British Isles to an international and global language. It emphasizes the language shifts that have taken place more recently since the widespread use of the Internet. The pervasiveness of the Internet has led to new changes in form and usage described as Internet English.
\end{abstract}

Keywords: CMC; electronic English; internetese; history of English; textese

From the eighteenth to the twentieth century, colonial and economic expansion saw the English language spread rapidly across the world to become a global language when the Internet was conceived. While all languages change over time, the Internet has introduced a new medium for these changes to take place. Since the Internet became publicly available, English spelling, pronunciation, vocabularies, and grammar, have changed, resulting in conflicting views and debate among language researchers and pundits. Some language researchers (e.g. Ali, 2012; Kern, 2006) alleged that the development of new English varieties, under the influence of the Internet, is a threat to the standard varieties of English. Such arguments emanate from the fact that the Internet English used on a daily basis today often does not conform to the standard varieties. On the other hand, established language researchers, such as David Crystal (2001, 2005, 2011), believe Internet English to be a linguistic revolution. To Crystal, these changes in English form and usage have given birth to a new branch of linguistics he calls Internet Linguistics. In academia today, Internet Linguistics is widely discussed within the realm of computer-mediated communication (CMC), digital communication, or the term, computer-mediated discourse analysis (CMDA) as coined by Herring (2001).

This paper intends to provide a bird's-eye view of the evolution of English in the Internet age with a focus on current stances. It analyses some recent linguistic research articles that have been conducted to identify common features of most recent linguistic phenomena in Late Modern English that coincided with the emergence of the Internet. Though it is hard to precisely determine the first existence of the Internet, this study highlights the language changes which became into effect under the influence of the internet invasion. It explores the historical developments in the English language as influenced by digital technology. The paper is specially intended to English learners taking courses in the history of English. It reads like an Introductory History of the English Language with a special focus on the period of the arrival of the Internet and WWW as the landmark in the many digital technologies.

\section{Rationale}

Being teachers of English, the authors felt the need for a summary of the history of English language so as to make L2 learners aware of the different varieties of English they deal with in their written texts; either those ancient literary texts such the Chaucerian Canterbury Tales, Shakespearean plays, T.S. Eliot's Waste Land or the current frequently used short messaging, emojis, and so on. This endeavor takes a historical perspective. It traces major changes that have taken place in English driven by the Internet in terms of spelling, pronunciation, grammar, the introduction of new eterms, the evolution of cybergenres, and digital tenor (Posteguillo, 2002). The study of such changes is rationalized by the fact that knowing the rules and 
features of Internet English would help language teachers and learners not only to keep abreast of the continuing developments in the language, which would help language instructions be relevant to the needs of learners but also to enlarge vocabulary and catch up with the pace of the highly moving society.

The Internet has changed traditional ways of interpersonal communication by offering an easy access to information and facilitating the exchange of information with people around the globe. Internet English has also exerted unprecedented effects upon English vocabulary through a constant influx of neologisms that can cause communication difficulties for non-Netizens ${ }^{i}$. These new words and argots are not limited to surfing the Internet but have become deeply integrated into daily life. Hence, feeling a little behind the times on technological lingo can lead one to unsuccessful social interactions in modern societies (Lee, 2001; Posteguillo, 2002).

Despite the fact that it is very well established that (a) digital technologies have driven language change and that (b) modern spoken English has taken on characteristics of CMC, and the phenomenon has been investigated - quite heavily in fact- it is worthwhile to compare the specific historical forces that influenced the History of the English Language (e.g. the Norman invasion) with specific historical influences on language change in the digital age. Likewise, it is also well established that spoken English has never had the level of formality that written English has. This paper shows how Internet English has made English less formal and provides some explanations as to why this happens.

\section{Historical perspective}

This section shows how English has evolved before becoming a global language and the advent of the Internet. Traditionally, the history of the English language has been divided into three major periods: Old English (450-1100), Middle English (11501500), and Modern English (1500-onwards). During these times, the language has undergone considerable changes since it was first transplanted to the British Isles by the Angles, Saxons, and Jutes in the fifth century. Their language (Old English or Anglo-Saxon) was derived from Proto-Germanic and gradually replaced the languages spoken by the Celtic peoples (Algeo, 2009; Baugh \& Cable, 2002).

After successive waves of Old English and Old Norse speakers immigrating to the British Isles, another major shift came in 1066 after the Norman invasion and defeat of the English (McCrum, Macneil, \& Cran, 1992). This change in political power had a significant influence on the Middle English period. French became the dominant language among the new ruling elites and the upper classes, causing French words to flood into English (Algeo, 2009). By the fourteenth century, English became dominant again but retained the large influx of French loanwords. About $40 \%$ of the words in Chaucer's Canterbury Tales published in 1388, for example, had a French origin (Algeo, 2009; Baugh \& Cable, 2002). Today, it seems to be difficult for the layperson to understand Middle English without translation into modern English. Having said this, this article is no way intends to dig into those varieties of Old and Middle English. Rather, it shows how the language has changed throughout the way until it has reached the current station of development.

English continued to grow and change during a period known as Modern English, which roughly dates from 1500 to the present day, distinguished from Middle English by the Great Vowel Shift, standardization, and a new influx of words from various languages. This period is often subdivided into Early Modern English and Late Modern English. After the sixteenth century, English speakers fanned out to establish colonies and trade throughout the world. Contact with the local languages of the colonies resulted in further waves of loanwords entering English. New words were also coined to meet the changing needs of the country.

During this time, numerous commentators called for standardization (Jackson, 2013; Wells, 1973). In the first half of the seventeenth century, the Royal Society in which John Locke was a member, argued for non-emotive, plain prose style for the language. In the eighteenth century, there was an attempt not only to formulate rules or principles by which correctness could be defined and achieved but also to seek order, stability, and identity (McCrum et al., 1992). There was also a demand to protect the language from change. John Dryden (1631-1700) expressed his worries by saying that "We have yet no prosodia, not so much as a tolerable dictionary, or a grammar so that our language is manner barbarous; ... I rather fear a declination of the language, than hope an advancement of it in the present age" (as cited in Wells, 1973, p. 39).

One reason was that English, unlike other major European languages, never had a language academy tasked with regulating an official version of the language (Considine, 2014). Two other needs for standardization were the creation of a dictionary and a common grammar and usage. Dr. Johnson's dictionary had a strong influence on standardizing English in both regards. In a paper published in the rambler while Dr. Johnson was working on the dictionary, he wrote, "I have labored to refine our language to grammatical purity and to clear it from colloquial barbarism". Speaking on pronunciation again, he stated, "the chief intent of it is to preserve the purity, and ascertain the meaning of our English idiom" (as cited in Jackson, 2013, p. 115). The main object of his dictionary was to 'save' the language 
from changes and vague usage. Thomas Sherdan (1719-1788) felt that Dr. Johnson's dictionary would supply the correctness and uniformity called for at the time. Sherdan commented, "If our language should ever be fixed, he (Dr. Johnson) must be considered by all posterity as the founder, and his dictionary as the corner stone" (as cited in Goring, 2005, p. 104).

During this period, there was also an adoption of a set of unified grammar rules (Considine, 2014; Goring, 2005; Jackson, 2013). Though scattered attempts had been made to find a single book of grammar since the sixteenth century, the idea became stronger and by the eighteenth century demands grew for a uniform grammar with three things in mind:

- $\quad$ To codify the principles of the language in rules.

- $\quad$ To settle disputed points and decide cases of divide usage.

- To point out common errors and thus correct and improve the language.

Grammarians during this period used Latin as a model and by the end of the eighteenth century, the attempt to standardize the language took shape. Some authors emphasized rhetoric to achieve stability, grammatical credibility, and refinement (Goring, 2005). Dr. Johnson's dictionary helped standardize meaning, pronunciation, and the parts of speech. While the British Empire was establishing a standard version of British English, The Americans wanted their own linguistic identity. Webster's dictionary, first published in 1828, helped establish another standard variety of the language.

As this overview has shown, in the past English had often undergone major changes due to population shifts, invasion, colonialism, and political upheaval. Arguably, before the eighteenth century, English did not have a standard form, nor did it in the $18^{\text {th }}$ century; and it still does not. The prescriptivists like Locke, Johnson, and Swift were fighting a losing battle from the beginning because the language changed throughout - it's always changing.

\section{English as a global language}

In the twentieth century, English expanded, becoming the national language not only of the British Empire, the United States, and their colonies but a global language. The international exchange of information between academics and professionals as well as the rise of the United States as a commercial and diplomatic hub also made the globalization of English possible. As a result, many countries chose English as a language of education, diplomacy, science, and technology as well as to remain competitive in the global job market. The $\mathrm{IT}^{\mathrm{ii}}$ sector, for instance, is one of many industries that have adopted English as its mother-tongue, and due to this position, English became the most common language on the Internet.

Cultural imperialism is another factor that has helped making English an international and global language. In countries where English is a foreign language (e.g., many Arabic-speaking countries), some books of English literature tend to be in wider circulation than books written in Arabic. By the mid-twentieth century, colonialism was quickly being replaced with cultural imperialism, especially after the global reach of US culture after World War II. There are many examples of this from Britain, France, and the US. One example is the US government asking France to allow more US films as payment for helping with reconstruction efforts after WWII. One more example, Arabic speakers use words and articles of clothing such as coat, jacket, jeans, and many other elements of a fashionable Western living. Japan, Russia, and China were initially very restrictive about the use of English but have now opted for using English to further their professional, industrial, and commercial advancement in a competitive global market (Mesthrie \& Bhatt, 2008). In a nutshell, English's pervasiveness was initially connected with the political expansion of the British Empire, but its expansion now obviously depends on its use in education, science, business, industry, diplomacy, and tourism.

The rise of meteoric English in the twentieth century was chiefly due to two major impulses: its colonial legacy (the British Empire and American expansionism) and later on US technological and economic hegemony. There were shifts in the needs, significance, and roles of English in both cases. By the early nineteenth, the British Empire had colonized numerous parts of the world in North America, South Asia, Africa, and Australia. The British Empire controlled the seas in the nineteenth century. "In Europe, Africa, Asia, and the Pacific millions of people came into regular contact with English who would not otherwise have had much (or anything) to do with it" (McArthur, 2006, p. 369). In the British colonies, English was the official language and later became an important second language during the post-colonial period. Since the old colonies often remained tied economically, if not politically, to their former colonial rulers, they used English as the language of government, commerce, and schools.

However, in the twentieth century, British and US political and economic power coincided with the growth of science and international commerce. Large numbers of words, such as electron, proton, neutron, quantum and relativity in general physics and $x$-ray, infrared, CT-scan, genetic code, testtube, and AIDS in the medical sciences, were added to the language. However, in many cultures where English was adopted, such as in Hawaii, Nigeria, and the Caribbean Islands, English went through 
greater changes and new language varieties emerged, gradually distancing themselves from either American or British English (McCrindle \& Wolfinger, 2011; Mesthrie \& Bhatt, 2008).

Looking at the historical evidence, it can be said that the rise of a language requires power in some forms to back it up. After the Second World War, the British Empire's held on its colonies weakened and gave way to the rise of the United States as a political and economic super power, which essentially replaced the British Empire's influence on the spread of the language (Baugh \& Cable, 2002; McArthur, 2006). Economic globalization, the emergence of international relations and online communication have made English a medium of global communication. This new shift began more in the second half of the twentieth century with the dominance of US television programming, satellite TV, and the film industry. English also became the dominant language of science and technology and the mothertongue of the computer industry. Computers have invaded homes, businesses, and institutions transforming the way we think, live, communicate, and manage time. The rapid change in technology has transformed and redefined both private and social spaces, thus reshaping language. McCrindle and Wolfinger (2011) stated:

Technology, American culture, multiculturalism, and globalization are four forces shaping language today. Technology has done more than extending our vocabulary; it has changed the way we use language, communicate and express ourselves. It is the younger generations who are at the forefront of this language revolution. (pp. 22-23)

In the second half of the twentieth century, English was taught on a large scale to non-native English speakers under different labels, such as English as a foreign language (EFL), English as a second language (ESL), and lately English as a lingua franca (ELF) (Thornbury, 2006). English for special purposes (ESP) has also emerged; it branched into varieties serving different purposes in a wide range of disciplines. For instance, the most prominent subdivisions of ESP included- but not limited to- EAP which stands for English for academic purposes, EBP (English for business purposes), English for Internet purposes, English for Occupational Purposes (EOP). The social transformation of the Internet has created what could increasingly be called a global culture and language, yet this area of research has received inadequate attention.

\section{From bricks to clicks}

As touched on above, the English language has witnessed several changes in the way it is written and spoken throughout its history. The ancient bricks and pieces of tribal dialects which made the early structure of English in the Old period and developed later on into classical and standard forms of using the language has been now replaced - to some extent-by 'clicks' resulted from the tremendous development of the information technologies. In other words, the most noteworthy change is the ongoing shaping of a newly born variety of English driven by the fast-growing technological innovations, primarily the Internet. It would be useful to discuss these trends under what is called electronic English and, more technically, Internetese, and textese. These terms refer to forms of modern English varieties which have been widely acknowledged in the literature.

\section{Electronic English}

Several language researchers have studied the changes that have taken place in written and spoken English from 1990 onwards. For instance, studies of Abu Sa'aleek (2015), Lyddy et al. (2014) and Cho (2010) show that a great historical linguistic change appears to be taking place within this period. Some of these studies, as explained below, analyzed electronic language use within formal contexts, i.e. a corpus of e-language used by L2 learners and brought about several categories that feature electronic English use. Researchers have also used various terms to refer to the language used by young people in electronic communication, such as the following as cited in Abu Sa'aleek (2015, p. 136):

\begin{abstract}
'electronic discourse' (Davis \& Brewer, 1997), 'electronic language' (Collot \& Belmore, 1996), 'Computer-Mediated Communication' (Herring, 1996), 'interactive written discourse' (Werry,1996), 'Netlish', 'Weblish', 'Internet language', 'cyberspeak', 'netling' (Thurlow, 2001), 'cyberlanguage' (MacFadyen, Roche, \& Doff, 2004), 'Netspeak' (Thurlow, 2001; Crystal, 2006), and 'virtual language' (Pop, 2008).
\end{abstract}

Whatever terms have been suggested, they essentially describe a unique variety of English conventionally referred to as electronic English. Recently, a high number of corpus studies has been documented. Several researchers have conducted corpus analyses of the linguistic and paralinguistic features of electronic English. Sun (2010, p. 103) studied the common and distinct patterns of wordformation and lexicon that Internet English shares with other varieties. The study showed four common characteristics of new terms: popularity, creativity, brevity and words with rich metaphorical meanings.

This language change, according to Crystal (2011), includes changes in vocabulary, orthography, grammar, pragmatics, and style (for more details, see Crystal, 2011). Hundreds of words and neologisms have been added to the English lexicon. A common change is the 'verbification' of nouns, such as to google, to text, to email. Perhaps, 
in today's faddish Internet-informed age, it is not always easy (or necessary) for everyone to differentiate standard or non-standard English as people often communicate online more than they do face-to-face or merge the styles since - as many have recently argued - the distinction between online and offline is no longer clearly differentiated, and we bring our communicative strategies and assumptions from the 'real world' to the keyboard and vice versa.

\section{The emergence of Internetese}

The Internet has ushered in new varieties of English with changes in vocabulary, grammar, spelling, and pronunciation. Linguists struggled to analyze these changes until Crystal (2005), Herring (Herring, 1996, 2001), among others, brought to the foreground the term Internet Linguistics to host the issues surrounding the rapid changes of the Internet English. The Internet has increasingly been used for language learning and teaching, gradually becoming a necessity for language program worldwide. Under the auspices of the Internet, a flood of new words has been created and used. This has been true of every major invention or event throughout history, though. Technological developments in the era of WWI and WWII and the 'space race' spawned countless new words. For instance, all the people using online communication are net citizens (abbreviated as netizens). Under the influence of the wider use of computers and online communication, it is remarkable that such computer-related words are very common today, such as software, windows, monitor, motherboard, keyboard, inkjet, laser, printer, file, modem, the Internet, e-mail, formatting, mouse, and the list goes on. Not only have these additions enriched the English language, but have also affected cultural identities. CMC has probably resulted in more than other historical events, but the phenomenon is not unique to the development of etechnology.

The Internet English has opened up new avenues of research. Changes in form and usage have caused some linguists to think of it as a new language called Internetese. In terms of frequency and scope of use, Internetese is currently the most prevalent medium for intercultural communication (Mesthrie \& Bhatt, 2008). For this reason, it has attracted a good deal of attention from all areas of linguistic enquiry (e.g., sociolinguistics, computational linguistics, and psycholinguistics). The ever-evolving English language is always unveiling new words and phrases, something even more evident since the rise of ubiquitous social media networks such as Facebook and Twitter. Social media has been also responsible for giving new uses to some existing words. For instance, today it is common to use the word 'friend' -which is a noun - as a verb such as 'to friend/unfriend somebody on FB'. Other examples include 'google it', 'twit on twitter', and so on.

In fact, internet usage generates new phenomena that affect the language at large, such as the interaction and exchange of information among an ever increasing number of speakers of English as L2 through email systems and websites (Crystal, 2006, 2011; Sun, 2010). Although much of this electronic language, as Crystal (2001) believes, is non-standard, playful, highly deviant in bending the standard rules of language, tolerant of typographic and spelling errors, and full of new and weird words, Crystal (2005) argues that "it should be exulting that the Internet is allowing us to once more explore the power of the written language in a creative way" (p. 2).

Tracing recent changes in the way of shaping modern varieties of English is possible by looking into computer-mediated communication (CMC) - a growing field of research. Online interlocutors today innovatively come into contact by using some strategies which differ from those used in fact-toface communication. There is already a great deal of research on CMC in Pragmatics, Sociolinguistics, Communication Studies, and Discourse Analysis/Critical Discourse Analysis. Here is a review of some relevant studies. Cho (2010), for instance, studied the linguistic features of email in the workplace. The study concluded that a combination of social and economic factors influences email style. The variety of English used in emails tends to be less formal than other varieties of written workplace communication. Besides being more readable and economical, a common feature of English used in emailing is what traditionally considered 'oral' or 'speech-like'. The study showed that this informal, conversational flavor that characterizes email English (emailese) is quite different from the other forms of workplace writing. Nevertheless, in a one-way analysis of variance, Yates (1996) found that "CMC is more akin to writing than speech in terms of range of vocabulary used" (p. 35).

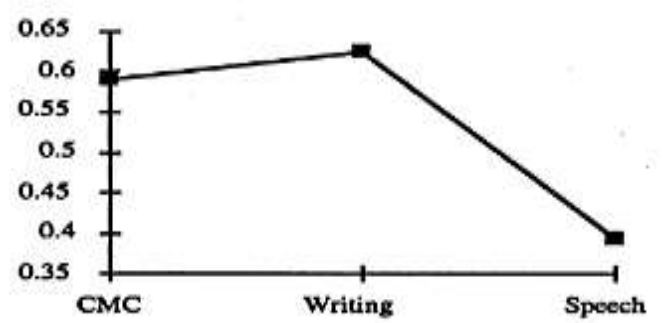

Figure.1 Yates' Interaction plot of type/token ratios for CMC, writing, and speech

Similarly, Kadir, Maros, and Hamid (2012) studied the linguistic features used in a discussion forum among the e-distance learning students in 2009 in the University Teknologi MARA Malaysia. The study analyzed 110 messages posted by 
students to their friends and lecturers. The study found patterns that the participants used in their online messages included shortenings, contractions, acronyms and initialisms, letter/number homophones, accent stylization particular pronunciation, speech, and non-alphabetic symbol. The participants also used emoticons, nonconventional spellings, and clippings.

In a similar vein, Abu Sa'aleek (2015) analyzed 340 messages collected from 160 undergraduate students' e-discourse in the Department of English Language and Translation in the Unaizah Community College and the Arts and Science College at Qassim University in Saudi Arabia. Similar to the study by Kadir, et al. (2012), Abu Sa'aleek's (2015, p. 138) study was an analysis of the linguistic features of electronic discourse. The study categorized the features as follows:

- Shortening

- Clippings

- Contractions

- Unconventional Spellings

- Word-Letter Replacement

- Word-Digits Replacement

- Word Combination

- Initialisms

- Emoticons

Averianova (2012, cited in Abu Sa'aleek, 2015, p. 137) stated that

\begin{abstract}
"The unique linguistic and iconographic features of electronic writing comprise but are not limited to the innovative abbreviation (acronyms, clippings, logograms, or letter-numeral hybrids and lettermorpheme substitutes, vowel deletion, etc.), emoticons, truncated simplified syntax, nonnormative capitalization, and other characteristics."
\end{abstract}

In order to present a more generalizable representation of the investigated phenomenon, $\mathrm{Abu}$ Sa'aleek (2015) suggested further research to be conducted with a larger sample of language users "to investigate other aspects of e-discourse" (p. 143). Likewise, Kadir, et al. (2012) recommended further research on "code-switching" and "synchronous and asynchronous" (p. 280) modes of communication.

In the same line of research, Lyddy et al. (2014) examined 13 characteristics of e-discourse. The corpus consisted of 936 English text messages (SMS/IM), with a total of 13.391 words in addition to 676 segments and weird expressions (i.e. symbols, emoticons, punctuation marks, etc.). The target population was young adults. The statistical analysis of the data indicated that one in four of the messages contained unconventional spelling. The findings also showed that dropping capital letters was the most common occurrence in the collected corpus.
Similarly, Tagliamonte and Denis (2008) examined the language of instant messaging. They analyzed a corpus of over a million words of instant messages. The results revealed that instant messaging (IM) is common in today's communication. The authors argued that instant messaging is a distinctive new hybrid of language made of a combination of formal and vernacular varieties of English. In addition, the results demonstrate that there was a variation and linguistic change in contemporary English.

\section{Textese (or texting)}

Linguists have been trying to frame all of these linguistic changes, believing that they collectively have resulted in a new variety or genre of English that has been increasingly used in day-to-day communication. Crystal (2008) refers to this communication as "texting"; while others prefer the term "textese". In this article, the term 'textese' is used. The spread of textese was originally limited by abilities to charge for the service and the mobile phone penetration. In essence, this newly-born genre, according to Crystal (2008), "has evolved as a twenty-first-century phenomenon - as a highly distinctive graphic style, full of abbreviations and deviant uses of language, used by a young generation that doesn't care about standards" (p.7). Textese is commonly written faster and less carefully than other forms of writing. Obviously, written English on social networks or chat groups show that writing on such spaces tends to be less structured and more abbreviated. textese has been perceived as less correct, less complex, and less coherent than other forms of language use.

There is a growing literature showing that the term textese has its own orthographical, phonological, morphological and syntactic features that make it stand alone as a unique form of modern English (Ahmed \& Al-kadi, 2016; Al-Kadi, 2017; Crystal, 2008). However, there is no consensus on the definition of the term 'textese. Several attempts to define it have been suggested. It is generally mooted as a genre of English characterized by using abbreviations and slang expressions and weird spelling with typographical errors, and it is commonly used in on mobile phone text messaging and other internet-based communication such as email and instant messaging. Linguistically speaking, it lacks those linguistic characteristics of the Standard English including the norms of sentence structure, pronunciation, punctuation, and so on. The ever-growing textese is known for its features of odd word-formations (e.g. clippings and acronyms) which strikingly carry messages differently from their existence in formal English.

Recently, textese (or texting) have gained prominence over their antecedent 'internetese' or 'Netspeak'. The terms texting, textese, textism are frequently used terms in the literature. However, 
there is a degree of uncertainty around these terminologies. In fact, it is a new phenomenon developed in the early 1990s but did not take off until the early 2000 s. It is generally defined as 'text messaging' or 'wireless messaging'.

While textese has become a prominent feature of communicational English today (Crystal, 2008), it has created many linguistic concerns; it is not only fast, informal, and economical but lacks paralinguistic features of real-time communication (as opposed to face-to-face communication). Hence, textese and its predecessor, internetese, are an integral part of delivering messages among interlocutors today; they (internetese \& textese) impose a new linguistic style that employs more paralinguistic features to assist in delivering comprehensible messages (Al-Kadi, 2017). In this way, "interlocutors have to use other manipulation

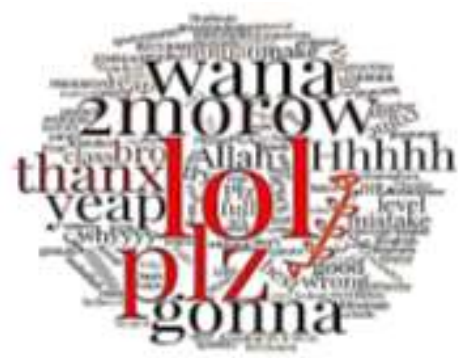

Figure 2. Word Clouds of Online Interlocutors' textese (Adopted from Al-Kadi, 2017)

As the figure shows, online communicators tend to use deviated language for reasons beyond description here. They use symbols (e.g. \# meaning hashtag), abbreviations (lol, r u 4 or 2?), emojis, and code-mixing so as to communicate in unique ways. In fact, this is a new avenue of research to explore cultural, social and other aspects of the phenomenon. It opens a wide space for research in this regard.

Actually, the advent of textese resulted from the development of social interaction online and via handheld devices. Driven by the small size of screens of such devices and the overwhelmed and huge amount of information on daily interactions, abbreviations have become the most common features of textese. Although English has had abbreviated words even in the pre-internet era, abbreviations now are tremendous and matchless. Earlier, words such as exam, vet, and fridge, for instance, are abbreviated forms of the words examination, veterinary, refrigerator. The shortened forms have effectively become new words and so familiar to common people now.

Punctuation is another characteristic feature of textese. English is one of the languages which lays heavy emphasis on punctuation marks, especially in its written forms. However, textese is deviant from the punctuation system or may dictate new functions to the known punctuation marks. Punctuations in textese stand not as punctuation marks the same way of written signs in order to accomplish pragmatic work that could be achieved through phonological variation, prosody, gesture and other cues in ordinary spoken conversation" (Kadir et al., 2012, p. 277). That is to say, since online interactions lack the facial expressions, gestures and conventions of body posture that are considered important when expressing ideas and opinions, the language users tend to use various ways to express themselves such as the use of emoticons, bold or block letters, etc.

Al-kadi (2017) studied how L2 learners contact with each other and with their teachers online (Facebook as a case in point). The author used a word cloud of the corpus collected from a sample of English learners and teachers (the results are shown in the following figure). Word cloud (A) was taken first and after a while Word Cloud (B) of the corpus was generated of the same informants.

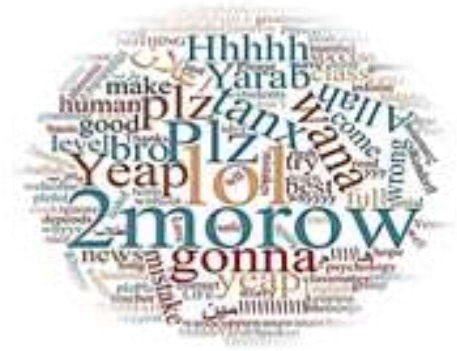

they do in formal English but as "messages" by themselves (as words/ phrase/sentence/). Hence, they are not treated as punctuation marks but they have their unique usage. Although this new variety can do without punctuation marks, it "runs the risk of ambiguity" (Crystal, 2008, p. 81). In 2004, Crystal (2004) published A Glossory of Textspeak and Netspeak in which he collected about 500 textSpeak abbreviations. There are several occurrences of punctuation errors in the corpus ranging from missing commas and full stops to wrong uses of full stops. Here are some examples:

- Incorrect uses of apostrophe

- Wrong uses of comma

- Incorrect uses of full stop

- Missing semi-colon or full stop (examples were provided)

Other Orthographic characteristics of textese are documented. There are six ways in which textese gives the impression of novelty:

- pictograms and logograms

- initialism

- nonstandard spellings

- omitted letters

- shortenings

- genuine novelties

There is a need of digging into how and in what ways is textese similar to spoken language. 
Which linguistic features make textese different from speech, and a unique variety of modern English?

Discussing textese in L2 context is tempting. Ali, Hasnain, and Beg (2015) studied the effects of textese on English language comprehension by 90 university students in India. The informants were asked to write the Standard forms of 35 short forms commonly used on the Internet (as used by texters). The results showed that the bulk of these respondents were unaware of what those short forms stand for in the standard varieties of English. That is to say, the informants were unfamiliar with those abbreviations - they neither understood nor used these abbreviations. This suggests that abbreviations are not universal and cannot be understood by all internet users. While at one time abbreviations were the norms, some researchers have found lately that many classes of students hate (and seldom use) textese. They resist the abbreviations making use of the 'autofill' feature of many modern devices and applications. It is possible that autofill will put in the full words for the abbreviations.

In an earlier study in the same context (i.e. India), Ali (2012) assumed that text messaging in the form of SMS, emails, and chat may be useful tools to teach the standard varieties of English. The author maintains that textese is unavoidable in today's communication, and there is no way to stop it completely. Hence, language teachers should think of some ways of making their students able to differentiate between the standard vs. non-standard forms of English. The students must be aware of where and when textese can be used or not used.

Likewise, Javed and Mahmood (2016) attempted - through a quantitative study- to identify how graduate students use English in their daily life and the effects of textese on the traditional language usage. The study recruited 75 students to respond to a questionnaire. Despite the popularity of textese today, the results of the study showed that there is a distinctive border between formal English and textese. Textese has its own ways of usage, which differ -to a great extent -from the formal traditional forms. The authors concluded that it might be useful to show L2 students how to compare the standard vs. the nonstandard forms of English.

Arguably, as technology develops and becomes more sophisticated, linguistic disasters are expected. Textese has been no exception to such predictions. According to Crystal (2008), it is a fairly popular belief that textese is a totally new phenomenon that affects the English language. Crystal maintained that textese is not affecting the major part of the Standard English. Textese is perceived as 'foreign,' 'alien,' and 'outlandish.' Textese is said to "masks dyslexia, poor spelling, and mental laziness." These statements seem to contradict one another - while this may have been truer in 2008, times and attitudes have changed.
Similarly, in a title of a wiki, Technology: Textese May Be the Death of English, Huang (2008) defined textese as "a nascent dialect of English that subverts letters and numbers to produce ultra-concise words and sentiments" (paragraph 1) and stated that it "is horrifying language loyalists and pedagogues" (paragraph 1). However, text is much more complex and fascinating than simple abbreviations, smiley face emoticons, and other weird symbols which most "texters" do not even utilize.

To sum up, textese is the most recent recognizable linguistic phenomenon. It is essentially an evolution of English in the Internet age which has taken different labels: Internetese, Emailese, Textese, and the like. While some language researchers (Ali, 2012; Kern, 2006) believe this new discourse of English is a deviant form of formal English $^{\text {iii }}$, Crystal $(2008,2011)$ thinks that it is a new genre of English varieties. This variety has been and still is evolving remarkably. Text messaging has been linguistically acknowledged as a new "genre" of modern English (Crystal, 2008; Prøysen, 2009).

\section{CONCLUSION}

This article has discussed how English has been changing under several forces. It has also explored how the quite recent and rapid changes under the auspices of the Internet applications has brought about news varieties of English which sound closer to informal oral discourse than to formal English. In addition, it has provided an overview of the development of English language from bricks to clicks - from its origins as a collection of tribal dialects of Anglo-Saxon that over time would gradually form a common language, having its standard forms until it has been reshaped under the influence of the Internet and other information and communication technologies. Throughout its history, English borrowed liberally from Norman French, Latin, and other languages it came into contact with. Standardization occured in the seventieth and nineteenth centuries. The scientific and technological revolutions of the twentieth century saw many changes in human life, which led to further changes in English. However, this time these changes were more rapid and widespread, leading to the Internet revolution.

After World War II, English was taught increasingly to non-native speakers of English due to economic incentives that have led to its becoming a global lingua franca. The different historical periods described have illustrated the changes in English that took place in form and usage. Earlier changes took longer to establish and were chiefly due to contact with speakers of other languages, such as Norman French. However, unlike the previous pace of language change, recent changes are taking place at a fast rate due to the influence of 
the Internet. These changes have prompted some linguists to adopt a new branch of linguistics (Internet linguistics), which analyzes new linguistic and paralinguistic features in the use of English today (see Ahmed \& Al-kadi, 2016; Crystal, 2011). Internet linguistics examines electronic English, which greatly differs from the conventional forms of English in terms of form and usage. With communication in modern life becoming faster paced, electronic English has become short and symbolic. The development of emoticons and other iconic inferences occur in a way that mimics earlier symbolic means of communication.

\section{ACKNOWLEDGMENT}

The authors would like to acknowledge the erudite professor Sage Graham from the University of Memphis for her comments on the preliminary version of this paper. She voluntarily accepted to go through it twice providing very useful comments to steer it along and bring it to fruition.

\section{REFERENCES}

Abu Sa'aleek, A. O. (2015). Internet linguistics: A linguistic analysis of electronic discourse as a new variety of language. International Journal of English Linguistics, 5(1), 135-145.

Ahmed, R. A., \& Al-kadi, A. M. T. (2016). Analysis of online texting among bilingual interlocutors. International Journal of English Language Education, 4(2), 131-147.

Algeo, J. (2009). The origins and development of the English language (6 edition). Boston: Wadsworth Publishing.

Ali, J. K. M. (2012). Influence of information and communication technology (ICT) on English language structure (Unpublished Ph.D. Dissertation). Aligarh Muslim University, Uttar Pradesh, India.

Ali, J. K. M., Hasnain, S. I., \& Beg, M. S. (2015). The impact of texting on comprehension. International Journal of Applied Linguistics and English Literature, 4(4), 108-117.

Al-Kadi, A. (2017). Some aspects of ICT uses in the teaching of EFL at the tertiary level in Yemen (Unpublished Ph.D. Dissertation). University of Carthage, Tunis, Tunisia.

Baugh, A. C., \& Cable, T. (2002). A history of the English language (5 edition). London: Routledge.

Cho, T. (2010). Linguistic features of electronic mail in the workplace: A comparison with memoranda.Language@Internet, 7(3). Retrieved from http://www.languageatinternet.org/articles/201 $0 / 2728$

Considine, J. (2014). Academy dictionaries 16001800. Cambridge: Cambridge University Press.
Crystal, D. (2001). Language and the Internet. Cambridge: Cambridge University Press.

Crystal, D. (2004). A glossary of netspeak and textspeak. Edinburgh: Edinburgh University Press.

Crystal, D. (2005). The scope of Internet linguistics. Paper given online to the American Association for the Advancement of Science meeting. Retrieved from http://allthingslinguistic.com/post/9447199392 4/the-scope-of-internet-linguistics

Crystal, D. (2006). Into the twenty-first century. In L. Mugglestone (Ed.), The Oxford history of English (pp. 394-413). New York: Oxford University Press.

Crystal, D. (2008). Texting. ELT Journal, 62(1), 7783.

Crystal, D. (2011). Internet linguistics: A student guide. New York: Routledge.

Goring, P. (2005). The rhetoric of sensibility in eighteenth-century culture. Cambridge: Cambridge University Press.

Herring, S. C. (Ed.). (1996). Computer-mediated communication: Linguistic, social, and crosscultural perspectives. Philadelphia: John Benjamins Publishing.

Herring, S. C. (2001). Computer-mediated discourse. In D. Schiffrin, D. Tannen, \& H. E. Hamilton (Eds.), The Handbook of iscourse analysis (pp. 612-634). Malden: Blackwell.

Huang, L. (2008). Technology: Textese may be the death of English. Newsweek. Retrieved from http://www.newsweek.com/technologytextese-may-be-death-english-87727

Jackson, H. (2013). Words and their meaning (3rd ed.). New York: Routledge.

Javed, S., \& Mahmood, M. (2016). Language change in texting: Situation analysis of graduate students. Journal of Literature, Languages and Linguistics, 26, 78-94.

Kadir, Z. A., Maros, M., \& Hamid, B. A. (2012). Linguistic features in the online discussion forums. International Journal of Social Science and Humanity, 2(3), 276-281.

Kern, R. (2006). Perspectives on technology in learning and teaching languages. TESOL Quarterly, 40(1), 183-210.

Lee, L. (2001). Online interaction: Negotiation of meaning and strategies used among learners of Spanish. ReCALL, 13(2), 232-244.

Lyddy, F., Farina, F., Hanney, J., Farrell, L., \& Kelly O’Neill, N. (2014). An analysis of language in university students' text messages. Journal of Computer Mediated Communication, 19(3), 546-561.

McArthur, T. (2006). English worldwide in the twentieth century. In L. Mugglestone (Ed.), The Oxford history of English (pp. 360-393). Oxford: Oxford University Press. 
McCrindle, M., \& Wolfinger, E. (2011). Word up: A lexicon and guide to communication in the 21 st century. New South Wales: Halstead Press.

McCrum, R., Macneil, R., \& Cran, W. (1992). The story of English. London: BBC Books.

Mesthrie, R., \& Bhatt, R. M. (2008). World englishes: The study of new linguistic varieties. Cambridge: Cambridge University Press.

Posteguillo, S. (2002). Netlinguistics and English for internet purposes. Ibérica, 4, 21-38.

Prøysen, S. (2009). The impact of text messaging on standard english (Unpublished Thesis). Universitetet i Bergen, Bergen, Norway.

Sun, H. (2010). A study of the features of internet English from the linguistic perspective. Studies in Literature and Language, 1(7), 98-103.
Tagliamonte, S. A., \& Denis, D. (2008). Linguistic ruin? Lol! Instant messaging and teen language. American Speech, 83(1), 3-34.

Thornbury, S. (2006). An A-Z of ELT. Oxford: MacMillan.

Wells, R. A. (1973). Dictionaries and the authoritarian tradition, a study in English usage and lexicography. Berlin: Mouton de Gruyter.

Yates, S. J. (1996). Oral and written linguistic aspects of computer conferencing: A corpus based study. In S. C. Herring (Ed.), Computermediated communication: Linguistic, social, and cross-cultural perspectives (pp. 29-46). Philadelphia: John Benjamins Publishing.

\footnotetext{
${ }^{\mathrm{i}}$ A netizen: an active participant in the online community of the Internet.

ii IT, standing for information technology, is a previously dominant generic term for interactive electronic media. It is now increasingly being replaced by the phrase Information and Communication Technology (ICT).

${ }^{\text {iii }}$ Formal English is used in this study as a synonym of the standard variety of written English.
} 